\title{
Brain and Eye Malformations Resembling Walker-Warburg Syndrome Are Recapitulated in Mice by Dystroglycan Deletion in the Epiblast
}

\author{
Jakob S. Satz, ${ }^{1,2}$ Rita Barresi, ${ }^{1,2}$ Madeleine Durbeej, ${ }^{1,2}$ Tobias Willer, ${ }^{1,2}$ Amy Turner, ${ }^{1,2}$ Steven A. Moore, ${ }^{3}$ and \\ Kevin P. Campbell $1,2,4,5$ \\ ${ }^{1}$ Howard Hughes Medical Institute and Departments of ${ }^{2}$ Molecular Physiology and Biophysics, ${ }^{3}$ Pathology, ${ }^{4}$ Neurology, and ${ }^{5}$ Internal Medicine, Roy J. and \\ Lucille A. Carver College of Medicine, University of Iowa, Iowa City, Iowa 52242
}

\begin{abstract}
Walker-Warburg syndrome (WWS) is a severe congenital disease that is characterized by brain and eye malformations and lethality during the first year of life. Genetic mutations have been identified in a subset of WWS patients, but a majority of clinical cases have unknown etiologies. POMT1 and POMT2, two of the causative genes, form an active enzyme complex in the posttranslational biosynthetic pathway of dystroglycan. Deletion of either Pomt1 or the dystroglycan gene causes early embryonic lethality in mice. Here we report that mice with epiblast-specific loss of dystroglycan develop brain and eye defects that broadly resemble the clinical spectrum of the human disease, including aberrant neuron migration, hydrocephalus, and malformations of the anterior and posterior chambers of the eye. Breaches of basement membranes coincide with the pathology, revealing an important function for dystroglycan in the morphogenesis of the brain and eye. These findings demonstrate the central role of dystroglycan in WWS and suggest that novel defects in posttranslational processing or mutations of the dystroglycan gene itself may underlie cases in which no causative mutation has been found.
\end{abstract}

Key words: Walker-Warburg syndrome; congenital muscular dystrophy; lissencephaly; hydrocephalus; microphthalmia; dystroglycan

\section{Introduction}

Walker-Warburg syndrome (WWS) is clinically defined by a spectrum of brain and eye malformations and congenital muscular dystrophy. Characteristic features of WWS include type II ("cobblestone") lissencephaly, hydrocephalus, pontocerebellar hypoplasia, microphthalmia, and retinal dysplasia and nonattachment (Dobyns et al., 1989; Muntoni and Voit, 2004). Muscle-eye-brain disease (MEB) and Fukuyama-type congenital muscular dystrophy (FCMD) have similar CNS involvement but less severe clinical presentations and longer survival than WWS, which is usually lethal during the first year of life (Muntoni and Voit, 2004).

Although the majority of WWS cases have unknown etiologies, $\sim 20 \%$ of WWS cases are linked to mutations in protein O-mannosyltransferase 1 (POMT1) (Beltrán-Valero de Bernabé et al., 2002). POMT1 associates with POMT2, and the heterodimer is capable of transferring an $\mathrm{O}$-mannosyl glycan to the $\alpha$-subunit of dystroglycan (Manya et al., 2004). Dystroglycan is composed of $\alpha$ and $\beta$ subunits that are encoded by a single gene,

\footnotetext{
Received May 31, 2008; revised Sept. 2, 2008; accepted Sept. 3, 2008.

This work was supported in part by the Paul D. Wellstone Muscular Dystrophy Cooperative Research Center Grant NS053672 and National Institutes of Health Grant NS041407. K.P.C. is an investigator of the Howard Hughes Medical Institute. We thank Michelle Tallquist and Philip Soriano for providing the Mox2-Cre mouse line and David Venzke and Sally Prouty for providing technical support. The WWS cerebral cortex tissue used in this study was provided by the National Institute of Child Health and Human Development Brain and Tissue Bank (HD83284).

Correspondence should be addressed to Kevin P. Campbell, 4283 Carver Biomedical Research Building, 285 Newton Road, lowa City, IA 52242-1101. E-mail: kevin-campbell@uiowa.edu. DOI:10.1523/JNEUROSCI.2457-08.2008

Copyright $\odot 2008$ Society for Neuroscience $\quad$ 0270-6474/08/2810567-09\$15.00/0
}

$D A G 1$, on chromosome $3 \mathrm{p} 21$ in humans (IbraghimovBeskrovnaya et al., 1993) and on chromosome 9 in mice (Górecki et al., 1994). The extracellular $\alpha$ subunit and the transmembrane $\beta$ subunit are posttranslationally cleaved and noncovalently associated (Ibraghimov-Beskrovnaya et al., 1993; Jayasinha et al., 2003). O-Glycosylation of the $\alpha$-subunit ( $\alpha$-dystroglycan) is essential for its high-affinity binding to both laminin and the laminin-like globular domains of agrin, perlecan, and neurexin (Ervasti and Campbell, 1993; Gee et al., 1994; Peng et al., 1998; Sugita et al., 2001).

The dystroglycan null mutation is lethal in mice at approximately embryonic day 6.5 (E6.5) (Williamson et al., 1997). Breaches of Reichert's membrane in the parietal wall of the dystroglycan null yolk sac suggested that the cause of lethality may be a loss of separation between the maternal and embryonic circulations. Deletion of Pomt1 or Fcmd, which encodes the putative glycosyltransferase fukutin, also results in embryonic lethality in mice as well as loss of $\alpha$-dystroglycan glycosylation and defects in the integrity of Reichert's membrane (Willer et al., 2004; Kurahashi et al., 2005), suggesting that posttranslational modification by POMT1 and fukutin is necessary for dystroglycan function during early mouse embryogenesis. Reichert's membrane is an extraembryonic structure that is specific to rodent development, and it is not known whether dystroglycan is necessary for survival of the human embryo. However, an in vitro study reported apoptosis and degeneration in dystroglycan null mouse embryoid bodies (Li et al., 2002), suggesting that dystroglycan may be necessary for survival of the mouse embryo. 
Here we report that dystroglycan expression and ligand-binding activity are disrupted in the WWS brain, and that the phenotype of mice with epiblast-specific loss of dystroglycan (MORE-DG null) broadly resembles the clinical spectrum of the human disease. In the MORE-DG null mice, breaches of basement membranes coincide with malformations of the brain and the anterior and posterior chambers of the eye, demonstrating an important role for dystroglycan in their morphogenesis. Together, these findings indicate a central role for dystroglycan in the pathogenic mechanism of the human disease, including the cases for which no causative mutation has been found.

\section{Materials and Methods}

Mutation analysis. Genomic DNA was isolated from human skeletal muscle using standard extraction protocols. The complete coding regions, including intron/exon boundaries, of DAG1, POMT1, POMT2, O-mannose $\beta-1,2-N$ acetylglucosaminyltransferase (POMGnT1), Fukutin-related protein (FKRP), fukutin, and $L A R G E$ were amplified by PCR (primers and sequences are available on request). The amplicons generated were purified and directly sequenced with the BigDye terminator cycle sequencing kit version 3.1 (Applied Biosystems). Sequences were analyzed on an ABI3130xl capillary Sequencer (Applied Biosystems). POMT1 and LARGE were sequenced by PreventionGenetics.

Generation of mice. Generation of the floxeddystroglycan and MORE-DG null mouse strains has been described previously (Cohn et al., 2002). Heterozygous floxed-DG/null (Dagllox/-) mice were bred to mice hemizygous for Mox2-Cre transgene (MORE mice) (Tallquist and Soriano, 2000). The heterozygous (Dag1+/-) mice carrying the Mox2-Cre transgene (Cre-Dag1+/-) were then bred with Dag1lox/lox mice, and heterozygous mice (Dag1lox/-) carrying the Mox2-Cre (Cre-Dag1lox/-) transgene were obtained. In an alternative breeding strategy, we bred heterozygous mice (Dag1lox/+) carrying the Mox2-Cre transgene (Cre-Dag1lox/+) with Dag1lox/ - mice to obtain Cre-Dag1lox/ - and mice homozygous for Dag1lox carrying the Mox2Cre transgene (Cre-Dag1lox/lox). Identical results were obtained by both breeding strategies. MORE mice were generously provided by Drs. Soriano and Tallquist (Mount Sinai School of Medicine, New York, NY). For analysis of the Mox2-Cre transgene expression, Cre-Dag1lox/+ and CreDag1 $+/-$ mice were crossed with the Z/EG reporter mouse strain (Novak et al., 2000) (Jackson Laboratories).

Protein biochemistry. Wheat germ agglutinin (WGA) enrichment was performed as described previously (Michele et al., 2002). Human or mouse brain was solubilized in Tris-buffered saline (TBS) containing 1\% Triton X-100 and protease inhibitors. The solubilized fraction was incubated with WGA-agarose beads (Vector Labs) for $24 \mathrm{~h}$. The beads were then washed with TBS containing $0.1 \%$ Triton X-100 and protease inhibitors, and the bound protein was eluted with TBS containing $0.1 \%$ Triton X-100, protease inhibitors, and $300 \mathrm{~mm} N$-acetyl D-glucosamine. Both the eluted fraction and the void were collected. Proteins were separated by $3-15 \%$ SDS-PAGE and transferred to polyvinylidene fluoride (PVDF) membranes. The PVDF membranes were blocked in 5\% Blotto and incubated with the primary antibodies overnight at $4^{\circ} \mathrm{C}$. The blots were developed by horseradish peroxidase enhanced chemiluminescence (Pierce).

Laminin overlay assay. The laminin overlay assay was performed as
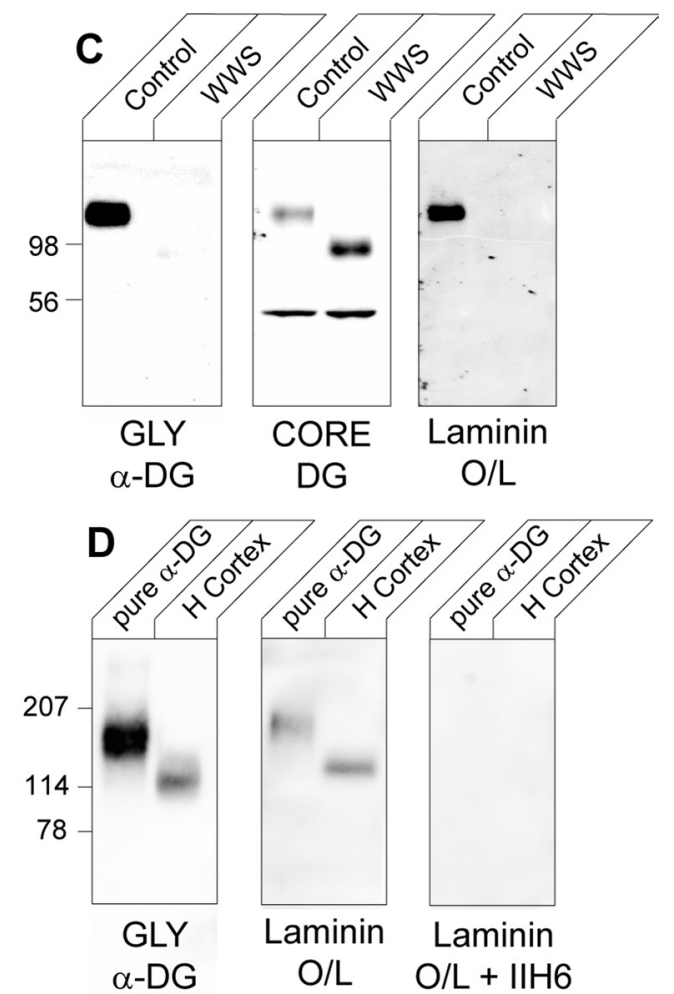

Loss of dystroglycan glycosylation and ligand binding in WWS brain. $A, B$, Sections of 6-month-old control $(\boldsymbol{A})$ and verlaid with laminin-1 (Laminin 0/L). D, Immunoblots of purified $\alpha$-dystroglycan from rabbit skeletal muscle and WGA-enriched

described previously (Ervasti and Campbell, 1993; Michele et al., 2002; Barresi et al., 2004). PVDF membranes were blocked in laminin-binding buffer (LBB; $10 \mathrm{~mm}$ triethanolamine, $140 \mathrm{~mm} \mathrm{NaCl}, 1 \mathrm{mM} \mathrm{MgCl}_{2}$, and 1 $\mathrm{mm} \mathrm{CaCl}_{2}$, pH 7.6) containing 5\% nonfat dry milk, incubated overnight at $4^{\circ} \mathrm{C}$ in LBB containing $7.5 \mathrm{~nm}$ mouse EHS (Engelbreth-Holm-Swarm) laminin-1 (Collaborative Biomedical Products), washed, and labeled with an antibody to laminin. For competition of laminin binding, PVDF membranes were incubated in LBB containing $0.75 \mathrm{~mm}$ IIH6 before the addition of laminin-1.

Histology and immunofluorescence. For histology, postnatal 2- to 4-week-old mice were deeply anesthetized with ketamine and perfused with 4\% paraformaldehyde. Embryos were killed by decapitation and immersion fixed in $4 \%$ paraformaldehyde. Adult or embryonic tissues were embedded in paraffin, and $5 \mu \mathrm{m}$ sections were cut on an RM2135 microtome (Leica). The sections were stained with hematoxylin and eosin, cresyl echt violet, luxol fast blue, or periodic acid Schiff and imaged on a DMRXA (Leica) or a BX41 (Olympus) microscope. For immunofluorescence, 3- to 4-week-old brains and eyes were fresh frozen in isopentane cooled by dry ice, and $8 \mu \mathrm{m}$ sections were cut on a CM3050S cryostat (Leica). The sections were fixed for $10 \mathrm{~min}$ in $2 \%$ paraformaldehyde and blocked for 30 min with 4\% BSA and 0.3\% Triton X-100 in PBS, before addition of antibodies. Images were acquired on a MRC-600 confocal microscope (Biorad).

Antibodies. The following antibodies were used: IIH6 (1:100) (Ervasti and Campbell, 1993), AP83 (1:100) (Duclos et al., 1998), Sheep5 (1:100) (Michele et al., 2002; Barresi et al., 2004), anti-laminin (1:1000) (Sigma L9393), anti-perlecan (1:1000) (Millipore Bioscience Research Reagents MAB1948), and anti-calbindin (1:1000) (Millipore Bioscience Research Reagents AB1778). IIH6, represented as GLY $\alpha$-DG in the figure legends, is a monoclonal antibody to the fully glycosylated species of $\alpha$-DG (Ervasti and Campbell, 1991). Sheep5, represented as CORE DG in the figure 


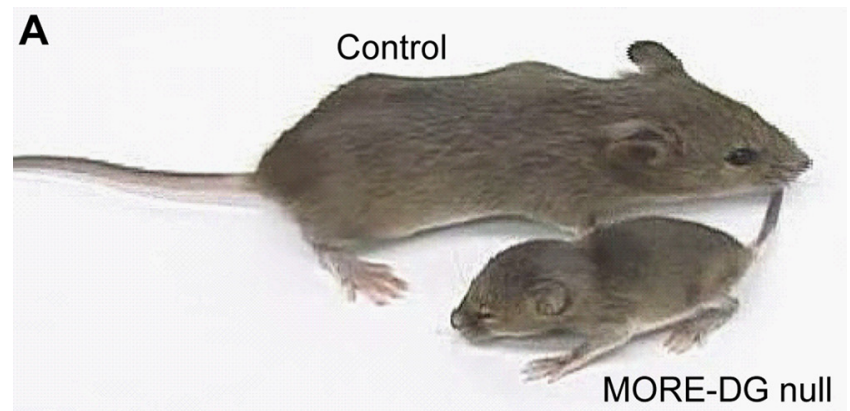

B

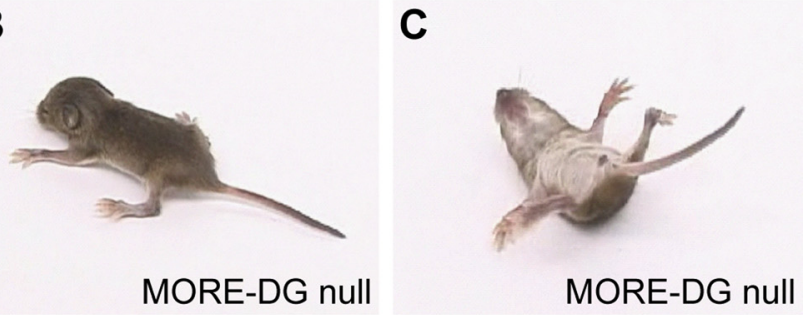

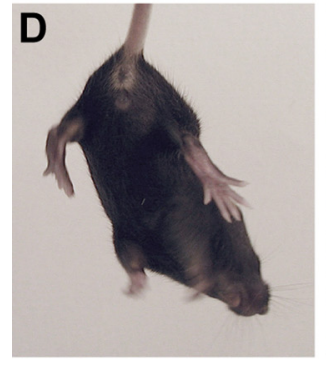

Control

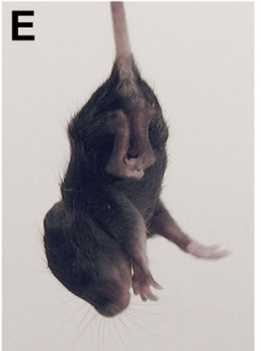

MORE-DG null
Figure 2. Dystroglycan-deficient (MORE-DG null) mice. A, A 27-d-old MORE-DG null mouse and a wild-type littermate. All of the dystroglycan-deficient mice were runted. B, C, A 27-d-old MORE-DG null mouse showing outstretched posture $(\boldsymbol{B})$ and delayed righting reflex (C). D-F, A 27-d-old wild-type littermate demonstrating a normal reaction (extension of hind and forelimbs) in response to tail suspension (D) and MORE-DG null mice demonstrating clasping behavior in response to tail suspension $(\boldsymbol{E}, \boldsymbol{F})$.

legends, is purified from sheep polyclonal antiserum raised against the whole dystrophin-glycoprotein complex and recognizes both $\alpha$ - and $\beta$-DG (Ibraghimov-Beskrovnaya et al., 1992).

\section{Results \\ Disruption of $\alpha$-dystroglycan glycosylation and ligand binding in Walker-Warburg syndrome brain}

Although brain involvement is prominent in WWS, the expression and glycosylation of dystroglycan have not been previously characterized in the WWS CNS. For this purpose, we obtained cerebral cortex of a male 6-month-old WWS patient from the National Institute of Child Health and Human Development Brain and Tissue Bank (HD83284). The clinical history of the donor included hypotonia and muscle weakness, microphthalmia and cataract of the left eye, agyria, and hydrocephalus affecting all ventricles (Kanoff et al., 1998). To confirm the presence of type II lissencephaly, we evaluated the brain by routine histological techniques. Reticulin staining of the WWS cerebral cortex demonstrated a high density of reticulin fibers (Fig. $1 B$ ), which are normally only associated with blood vessels, the glia limitans, and the arachnoid. The histology of the WWS cerebral cortex showed breaches of the glia limitans, fusion of adjacent gyri, and overmigration of neurons, which are features characteristic of type II lissencephaly (Fig. 1B).
The majority of WWS cases have no known genetic defect; however, $\sim 20 \%$ of cases are associated with mutations of POMT1 (Beltrán-Valero de Bernabé et al., 2002), and a subset of WWS cases have also been associated with mutations in POMT2 (van Reeuwijk et al., 2005), POMGnT1 (Taniguchi et al., 2003), FCMD (Beltrán-Valero de Bernabé et al., 2003; Silan et al., 2003; Cotarelo et al., 2008), FKRP (Beltran-Valero de Bernabé et al., 2004), and LARGE (Godfrey et al., 2007; van Reeuwijk et al., 2007). We isolated genomic DNA from the donor tissue and sequenced the coding regions (including intron/exon boundaries) of POMT1, POMT2, POMGnT1, FKRP, FCMD, and $L A R G E$, but we were unable to find a mutation in any of these known causative genes or in the gene encoding dystroglycan (data not shown). This result placed the patient in the large group of WWS cases with unknown etiologies.

To examine the expression of dystroglycan, WGA-enriched homogenates of WWS and control cerebral cortices were immunoblotted and probed with the IIH6 antibody, which is directed against a laminin-binding $\alpha$-dystroglycan glycoepitope, or the Sheep5 antibody, which is directed against peptide epitopes of $\alpha$-dystroglycan and $\beta$-dystroglycan, respectively (Fig. $1 C$ ). The $\alpha$-dystroglycan glycoepitope (left) was absent from the WWS cerebral cortex, and the molecular weight of the remaining $\alpha$-dystroglycan protein (middle, top band) was reduced from 120 to $\sim 90 \mathrm{kDa}$, consistent with a loss of protein glycosylation. In contrast, $\beta$-dystroglycan expression (middle, bottom bands) was comparable in the control and WWS cerebral cortices. Dystroglycan was not detected in the WGA voids (data not shown).

The loss of the IIH6 epitope in the WWS brain suggested that the ability of $\alpha$-dystroglycan to bind to laminin may be impaired. The reactivity of the IIH6 antibody is dependent on the glycosylation of $\alpha$-dystroglycan, and its epitope is lost after chemical deglycosylation (Ervasti and Campbell, 1993). Laminin binding is also lost after chemical deglycosylation, and it is blocked by competition with the IIH6 antibody (Ervasti and Campbell, 1993). To test whether the hypoglycosylated form of $\alpha$-dystroglycan that is present in the WWS brain is a functional laminin receptor, immunoblots were overlaid with laminin-1 protein and probed with an antibody to laminin. The laminin-1 overlay on WGA-enriched homogenates from the WWS cerebral cortex (Fig. 1C, right) showed no detectable dystroglycan/ laminin-binding activity. The specificity of the assay was confirmed by laminin overlay on immunoblots of $\alpha$-dystroglycan purified from rabbit skeletal muscle and WGA-enriched extracts of human brain (Fig. $1 D$, middle) as well as by laminin overlay in the presence of the IIH6 antibody to block dystroglycan/laminin binding (Fig. $1 D$, right).

\section{Generation of MORE-DG null mice}

To determine whether loss of dystroglycan function is capable of recapitulating the severe brain and eye malformations that are present in WWS, the Mox2-Cre transgene (Tallquist and Soriano, 2000) was used to selectively disrupt dystroglycan expression in the developing embryo. In the MORE-DG null yolk sac, dystroglycan expression was maintained at Reichert's membrane, although it was absent from the epiblast as early as E7.5 (supplemental Fig. $1 D$, available at www.jneurosci.org as supplemental material). At this stage of development, dystroglycan is normally present at the basement membrane between the visceral endoderm and ectoderm. Despite the loss of dystroglycan from this basement membrane, the epiblast and proamniotic cavity had normal histology.

Crosses between floxed-dystroglycan and Mox2-Cre mouse 
strains generated MORE-DG null mice at a $12 \%$ frequency corresponding to half the predicted Mendelian ratio (25\%). MORE-DG null mice were significantly smaller than control littermates at birth and throughout postnatal life (Fig. $2 \mathrm{~A}$ ). In addition, the MORE-DG null mice exhibited tremor during motion and at rest, outstretched posture of hind and forelimbs, delayed righting reflex, profound muscle weakness, and hindlimb clasping (Fig. 2; supplemental Video, available at www. jneurosci.org as supplemental material). A majority of the mice died within $48 \mathrm{~h}$ of birth, and the remaining mice typically failed to survive the fourth postnatal week. Routine histology of neonatal quadriceps indicated that muscular dystrophy was present at birth (data not shown). Although the brains of the runted MORE-DG null mice were smaller in size than the brains of littermate control mice, the gross anatomical structure was comparable, except that the cerebella were disproportionately small (Fig. 3B; supplemental Fig. 2, available at www. jneurosci.org as supplemental material).

To confirm the spatial pattern of Mox2-Cre expression in the brain and eye, the Mox2-Cre mice were crossed with Z/EG reporter (Novak et al., 2000) mice in which enhanced green fluorescent protein (eGFP) expression is activated by Cre recombinase. Fluorescence detection of the eGFP reporter expression indicated robust expression of the MOX2-Cre transgene in whole mount (supplemental Fig. $1 F$, available at www.jneurosci.org as supplemental material) as well as sections throughout the brain (data not shown) and retina (supplemental Fig. 1G, available at www. jneurosci.org as supplemental material). We confirmed the loss of dystroglycan expression in the MORE-DG null brain by immunoblot of WGA-enriched homogenates of whole brain (Fig. 3C) and immunofluorescence of brain sections (Fig. $3 E$ ) labeled with antibodies to dystroglycan. The MORE-DG null brain showed no detectable $\alpha$-dystroglycan expression by immunoblot, but a faint trace of $\beta$-dystroglycan was detected on overexposure (Fig. 3C). Dystroglycan was not detected in the MORE-DG null brain by immunofluorescence (Fig. 3E).

Dystroglycan is normally localized to glial endfeet, which form basement membranes at glial interfaces abutting the brain vasculature and the surface of the brain (glia limitans). The integrity of these basement membranes was examined by immunofluorescence detection of laminin and perlecan. The MORE-DG null brain showed preserved perivascular laminin and perlecan; however, the localization of these proteins was discontinuous at the glia limitans on the surface of the cere-

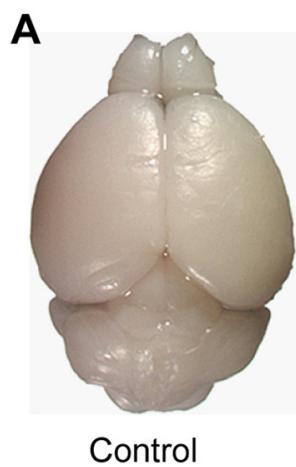

B
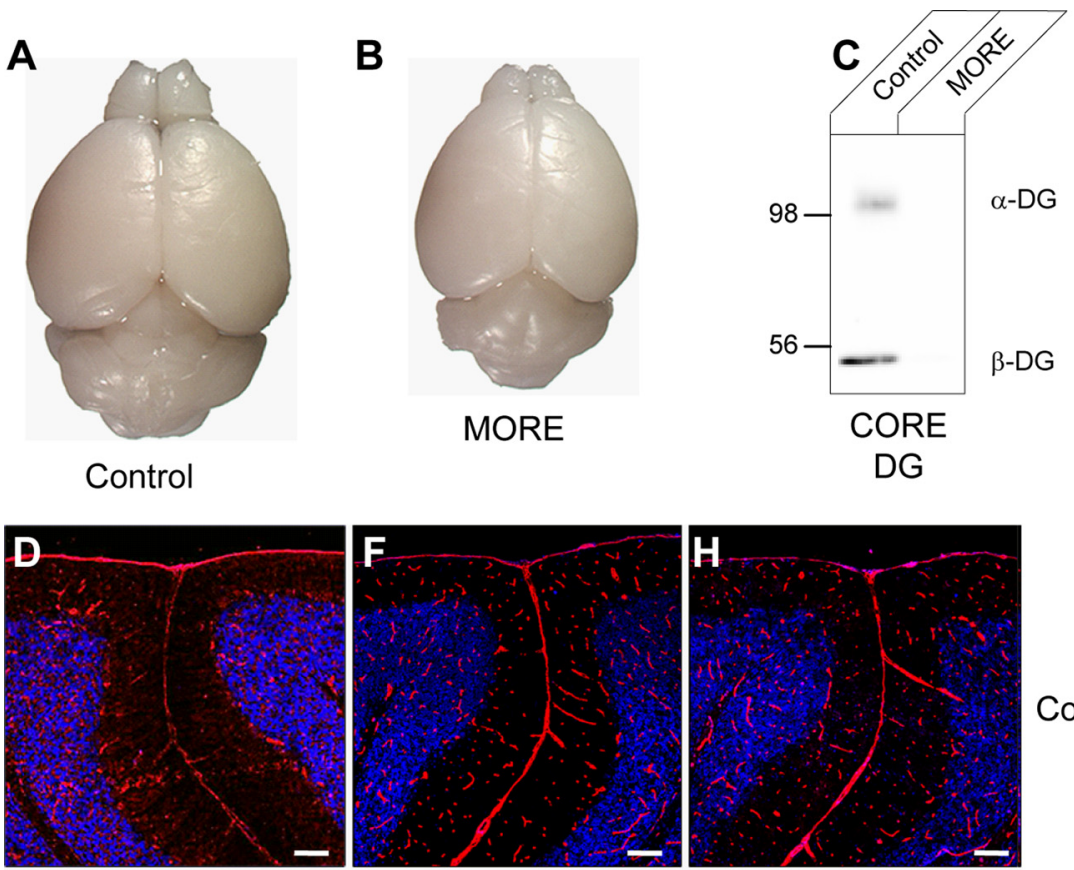

Control

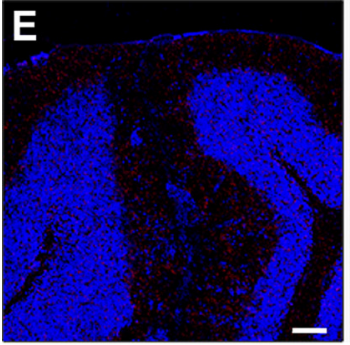

DG
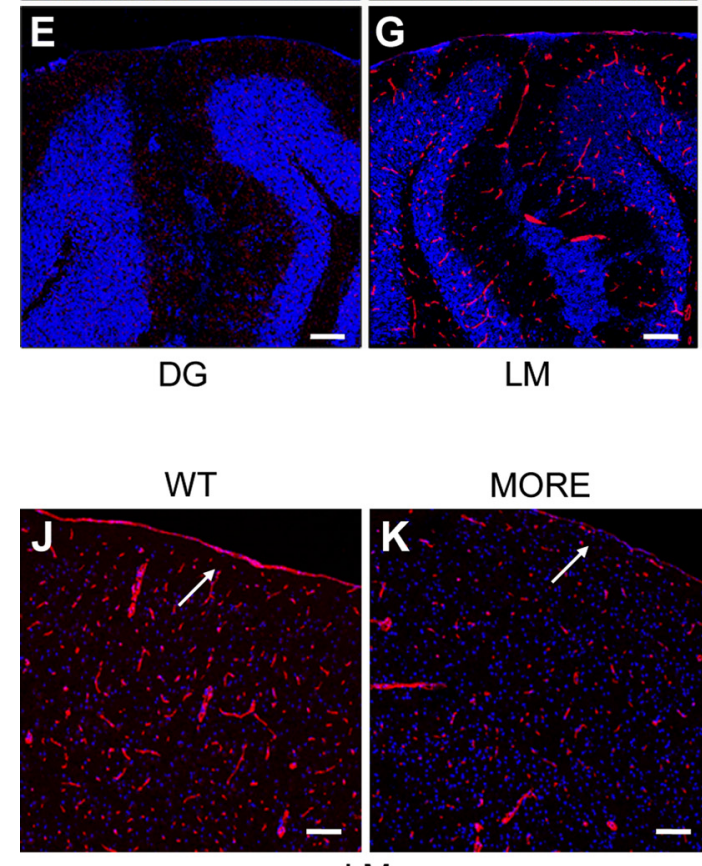

LM

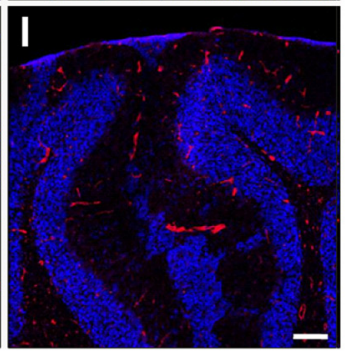

PER
Figure 3. Dystroglycan loss in the MORE-DG null brain. $\boldsymbol{A}, \boldsymbol{B}$, Postnatal day 27 wild-type littermate control $(\boldsymbol{A})$ and MORE-DG null $(\boldsymbol{B})$ brains. $\boldsymbol{C}$, WGA-enriched homogenates of wild-type littermate control and MORE-DG null brain labeled with antibodies to $\alpha$ - and $\beta$-dystroglycan, confirming the loss of dystroglycan expression in the dystroglycan-deficient mouse. $D-I$, Immunofluorescence detection of dystroglycan $(\boldsymbol{D}, \boldsymbol{E})$, laminin $(\boldsymbol{F}, \boldsymbol{G})$, and perlecan $(\boldsymbol{H}, \boldsymbol{I})$ in cerebellum sections from postnatal day 27 control $(\boldsymbol{D}, \boldsymbol{F}, \boldsymbol{H})$ and MORE-DG null $(\boldsymbol{E}, \boldsymbol{G}, \boldsymbol{I})$ mice. Dystroglycan expression was not detected by immunofluorescence in the MORE-DG null cerebellum. Perivascular localization of laminin and perlecan was preserved, but the proteins were discontinuous at the glia limitans. $\boldsymbol{J}, \boldsymbol{K}$, Immunofluorescence detection of laminin in cerebral cortex sections from 27-d-old control $(\boldsymbol{J})$ and MORE-DG null (K) mice. Nuclei are counterstained with $4^{\prime}, 6$-diamidino-2-phenylindoledihydrochloride. Arrows point to the glia limitans. $\boldsymbol{L}$, Immunoblot of WGA-enriched homogenates of wild-type and MORE-DG null brain overlaid with laminin. MORE, MORE-DG null; LM, laminin; PER, perlecan; WT, wild type. Scale bars, $100 \mu \mathrm{m}$.

bellum (Fig. 3G,I) and the cerebral cortex (Fig. 3K). Laminin overlay on immunoblots of WGA-enriched brain lysates, which specifically detects the interaction of dystroglycan and laminin, confirmed the loss of dystroglycan expression and loss of laminin binding in the MORE-DG null brain (Fig. $3 L$ ). 


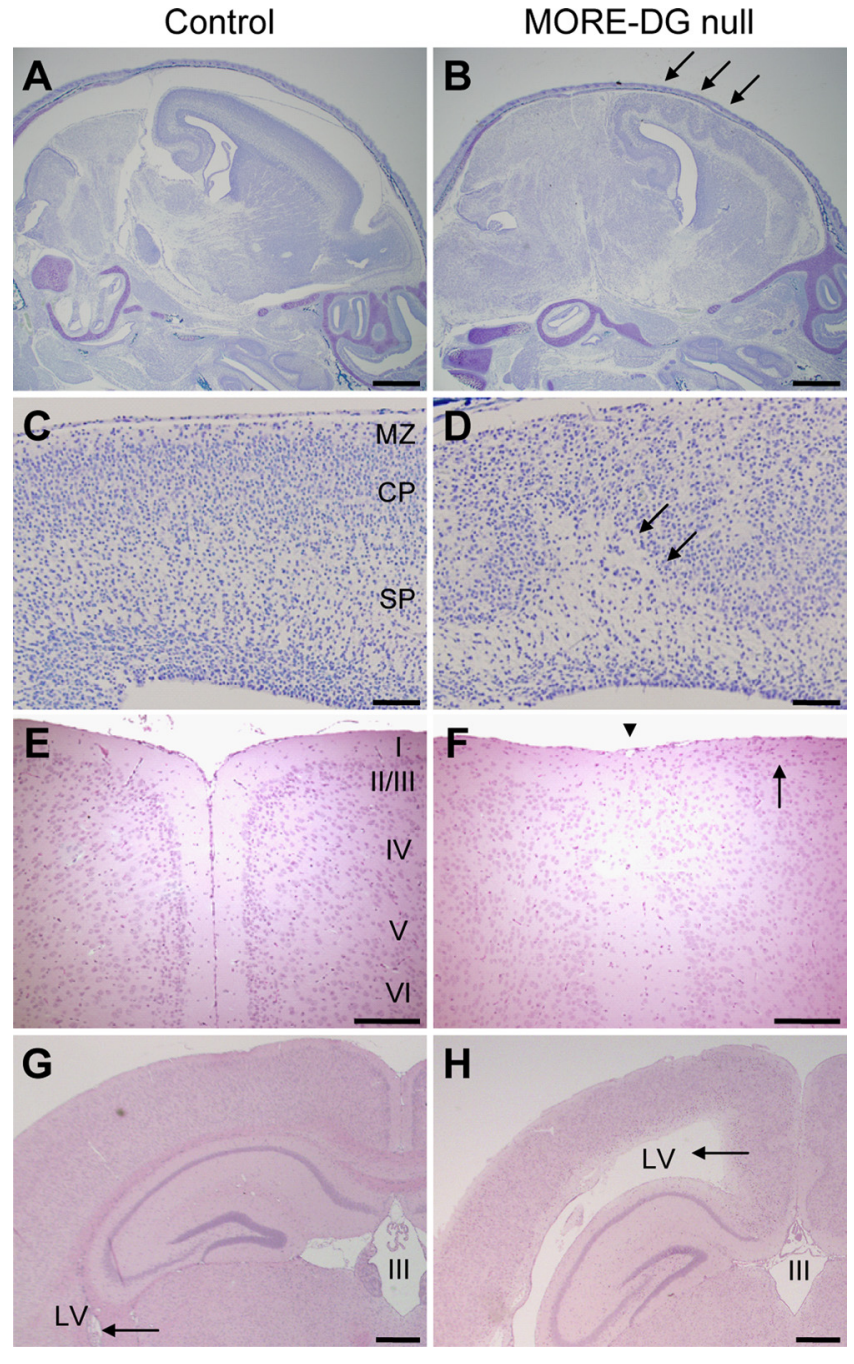

Figure 4. Cortical dysplasia and hydrocephalus in MORE-DG null mice. $A-D$, Sections of embryonic day 18.5 wild-type littermate control $(\boldsymbol{A}, \boldsymbol{C})$ and MORE-DG null $(\boldsymbol{B}, \boldsymbol{D})$ brains stained with cresyl violet. The abnormal lamination of the cortical plate in the MORE-DG null mouse ( $\boldsymbol{B}$, $D$, arrows) is reminiscent of human polymicrogyria. $E, F$, Coronal sections of wild-type littermate $(\boldsymbol{E})$ and MORE-DG null $(\boldsymbol{F})$ cerebral cortices stained with hematoxylin and eosin, showing fusion of the cerebral hemispheres ( $\boldsymbol{F}$, arrowhead) and diffuse neuronal-glial heterotopia $(\boldsymbol{F}$, arrow) at the surface of the dystroglycan-deficient cerebral cortex. $\boldsymbol{G}, \boldsymbol{H}$, Coronal sections through wild-type littermate control $(\boldsymbol{G})$ and MORE-DG null $(\boldsymbol{H})$ brains stained with hematoxylin and eosin. Arrows mark the lateral ventricles, highlighting the enlarged lateral ventricle in the dystroglycan-deficient mouse. Scale bars: $\boldsymbol{A}, \boldsymbol{B}, 1 \mathrm{~mm} ; \boldsymbol{C}, \boldsymbol{D}, 100 \mu \mathrm{m} ; \boldsymbol{E}, \boldsymbol{F}, 500 \mu \mathrm{m} ; \boldsymbol{G}, \boldsymbol{H}, 1$ $\mathrm{mm}$. MZ, Marginal zone; $\mathrm{CP}$, cortical plate; SP, subplate; LV, lateral ventricle.

\section{Early embryonic loss of dystroglycan causes hydrocephalus and aberrant neuron migration}

Type II lissencephaly and enlargement of the lateral ventricles, with or without progressive hydrocephalus, are common diagnostic criteria for WWS (Muntoni and Voit, 2004). Type II lissencephaly is characterized by a disruption of cerebral cortical layering, overmigration of cerebral cortical neurons, and obliteration of the subarachnoid space by glial and neuronal heterotopia (Pagon et al., 1978; Whitley et al., 1983; Choi and Matthias, 1987). The histology of the embryonic and postnatal MORE-DG null cerebral cortex demonstrated disruptions of the glia limitans, overmigration of neurons, and the presence of diffuse glial/ neuronal heterotopia (Fig. 4), which closely resemble the pathology in human type II lissencephaly. Sections through the embryonic brain revealed wave-like disruptions of the cortical plate by neuronal and glial heterotopia (Fig. $4 B, D$ ). Examples of neural tube closure defects (e.g., exencephaly and meningomyelocele) or holoprosencephaly were not observed in the embryos. Coronal sections of the cerebral cortex showed midline fusion of the cerebral hemispheres (Fig. $4 F$ ) and enlargement of the lateral ventricles (Fig. $4 H$ ).

Hydrocephalus (Fig. $4 H)$ was present in $45 \%(n=5 / 11)$ of the MORE-DG null mice. Although the mouse colony has a C57BL/6J background, in which spontaneous hydrocephalus is reported to occur at a frequency of $0.03 \%$ (Jackson Laboratories), the percentage observed in MORE-DG null mice is significantly higher than the percentage reported for wild-type C57BL/6J mice, and we did not detect the malformation in the littermate control mice used in our study. The development of hydrocephalus in WWS has been attributed to several factors, including stenosis of the cerebral aqueduct and blockage of the arachnoid granulations by glial/neuronal heterotopia (Dobyns et al., 1989). Patent cerebral aqueducts were observed throughout serial sections of affected MORE-DG null brains (data not shown).

Cerebellar and brainstem involvement in WWS includes pontocerebellar hypoplasia and cerebellar dysgenesis (Dobyns et al., 1989). The histology of the MORE-DG null cerebellum revealed complete fusion of the cerebellar lobules as well as fusion of the midbrain and adjacent cerebellar lobules (Fig. $5 B, D$ ). The number of cerebellar lobules was preserved; however, the cytoarchitecture of the lobules was abnormal (Fig. 5A-H). Granule neurons had partially failed to migrate into the internal granule cell layer and were present between fused cerebellar lobules and on the surface of the cerebellum. Foci of Purkinje cells had overmigrated and were located in the molecular layer (Fig. $5 H$ ). Sections through the brainstem showed that the pyramidal tracts were virtually absent (Fig. 5J, asterisk).

Although almost all of the MORE-DG null mice showed complete loss of dystroglycan expression in the brain, one of the mice showed mosaic dystroglycan expression and developed milder pathology than mice with more complete loss of dystroglycan expression. In this mouse, immunofluorescence detection of dystroglycan showed mosaic expression of dystroglycan at the glia limitans (Fig. 6B,D). Interestingly, the cytoarchitecture of the cerebral cortex was relatively preserved at sites of residual dystroglycan expression, although adjacent portions of the cerebral cortex that lacked expression of dystroglycan were dysplastic.

\section{Malformations of the anterior and posterior chambers of the eye in dystroglycan-deficient mice}

Malformations of the anterior chamber of the eye, such as Peter's anomaly and corneal clouding, are common in WWS, and approximately one-half of the patients are affected by microphthalmia in one or both eyes (Dobyns et al., 1989). Microphthalmia occurred in one or both eyes of $91 \%(n=10 / 11)$ of the MORE-DG null mice (Fig. $7 A-C$ ). Although relatively mild microphthalmia has been reported to occur spontaneously in $4.3 \%$ of C57BL/6J mice (Chase, 1942), we did not observe comparable reductions in ocular size in the control littermates. Approximately $27 \%(n=3 / 11)$ of mutant mice appeared to have anophthalmia, but severely microphthalmic eyes may have been present previously and degenerated.

Severe anterior chamber malformations were found in the eyes of $18 \%(n=2 / 11)$ of MORE-DG null mice (Fig. $7 C, D)$. Lens and iris tissue was herniated through the cornea (Fig. $7 C, D, F$ ), and this compromise in structure may have led to the eye degeneration in some cases. The microphthalmic eyes presented small or absent lenses (Fig. 7F). Periodic acid Schiff stain was used to 

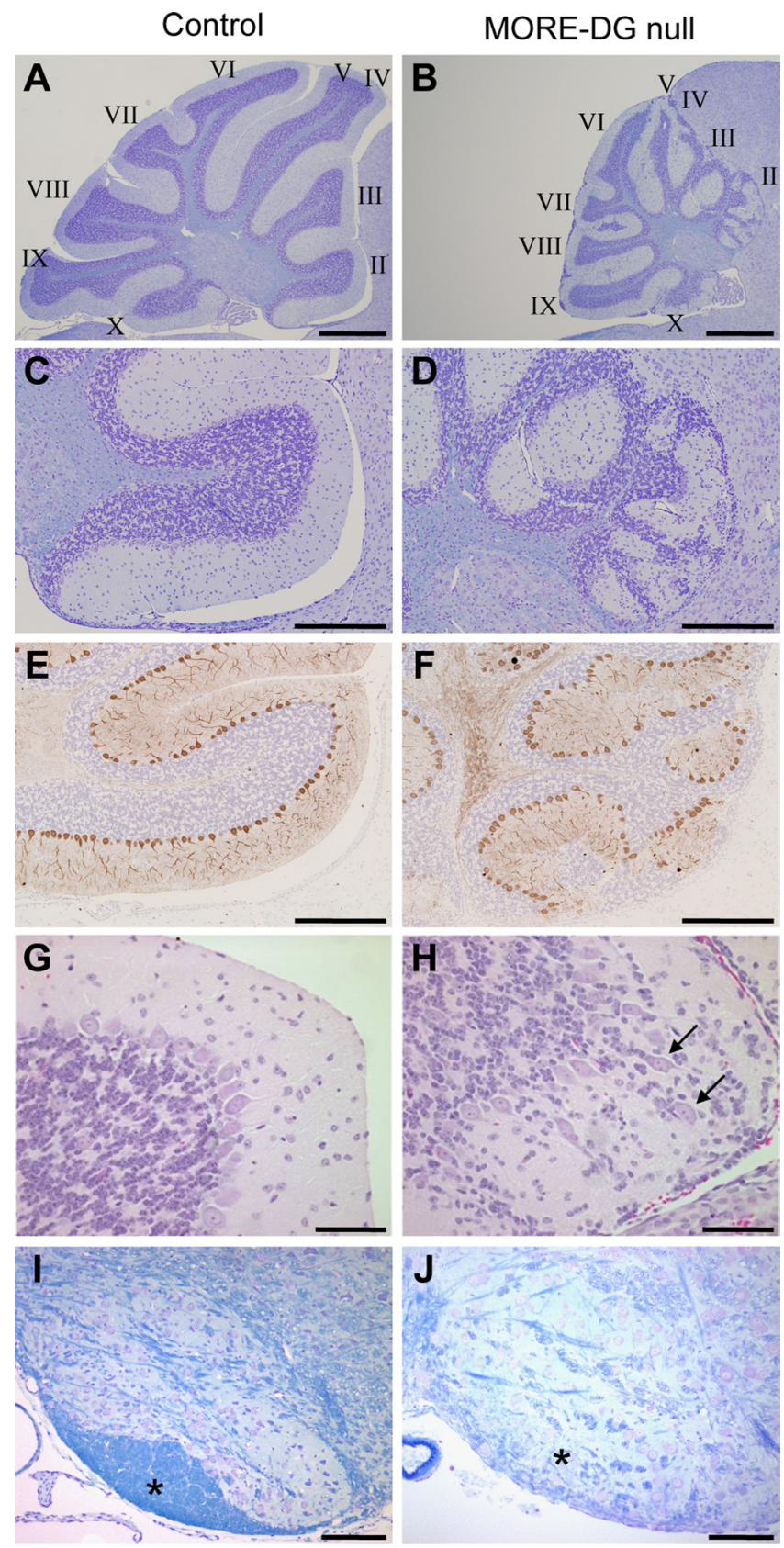

Figure 5. Cerebellar dysplasia and hypoplasia of the pyramidal tracts in MORE-DG null mice. $A-D$, Micrographs of the cerebella from littermate control $(A, C)$ and MORE-DG null $(B, D)$ mice at postnatal day 27 stained with cresyl violet and luxol fast blue. In the MORE-DG null cerebellum, there is complete fusion of the cerebellar lobules, pockets of ectopic granule neurons on the surface of the cerebellum and between the fused folia, and fusion of the cerebellum and midbrain. $\boldsymbol{E}, \boldsymbol{F}$, Micrographs of the cerebella of littermate control $(\boldsymbol{E})$ and MORE-DG null $(\boldsymbol{F})$ mice at postnatal day 27 labeled with an antibody to calbindin showing abnormal cytoarchitecture in the MORE-DG null mouse. $\mathbf{G}, \boldsymbol{H}$, Micrographs of the cerebella of littermate control $(\boldsymbol{G})$ and MORE-DG null $(\boldsymbol{H})$ mice at postnatal day 27 stained with hematoxylin and eosin. In the MORE-DG null cerebellum, there were foci of Purkinje cells that were mislocalized in the molecular layer. $I, J$, Luxol fast blue-stained sections through the brainstems of wild-type littermate $(I)$ and MORE-DG null $(\boldsymbol{J})$ mice, showing a near absence of pyramidal tracts (asterisks) in the dystroglycan-deficient mouse. Scale bars: $\boldsymbol{A}, \boldsymbol{B}, 1 \mathrm{~mm} ; \boldsymbol{C}-\boldsymbol{F}, 500 \mu \mathrm{m} ; \boldsymbol{G}-J, 100 \mu \mathrm{m}$.

highlight basement membrane structures. Dystroglycandeficient eyes with the severe anterior chamber malformations showed disruption of the corneal endothelium and Descemet's membrane, as well as continuity of corneal and iris tissues (Fig. $7 H$, arrow).
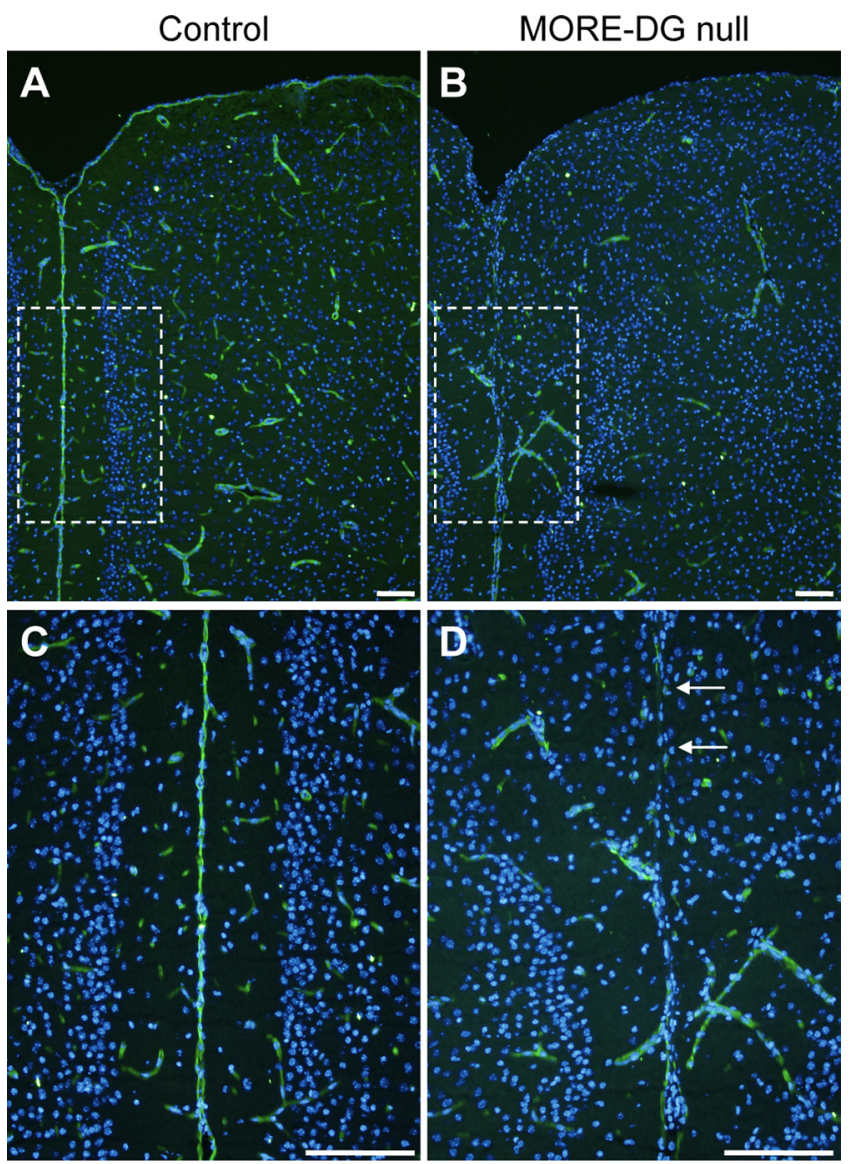

Figure 6. Mosaic expression of dystroglycan and preservation of cortical lamination. $A-D$, Coronal sections of wild-type littermate $(\boldsymbol{A}, \boldsymbol{C})$ and MORE-DG null $(\boldsymbol{B}, \boldsymbol{D})$ cerebral cortex stained with an antibody to $\alpha$-dystroglycan (green) and counterstained with $4^{\prime}, 6$-diamidino-2phenylindoledihydrochloride. Regions of residual dystroglycan expression showed preserved cerebral cortical cytoarchitecture, whereas adjacent regions that lacked dystroglycan expression ( $\boldsymbol{D}$, arrows) contained glial and neuronal heterotopia. Mosaic expression was rarely observed in MORE-DG null mice. $\boldsymbol{C}, \boldsymbol{D}$, High-magnification view of boxed regions in $\boldsymbol{A}$ and $\boldsymbol{B}$, respectively. Scale bars, $100 \mu \mathrm{m}$.

Immunofluorescence labeling of laminin revealed disruptions of the lens capsule as well as fusion of lens and corneal tissue, phenotypes that are reminiscent of Peter's anomaly (supplemental Fig. 3, available at www.jneurosci.org as supplemental material). The loss of dystroglycan expression in the lens, cornea, and iris was confirmed by immunofluorescence analysis (supplemental Fig. 3, available at www.jneurosci.org as supplemental material).

Retinal malformations are a consistent feature of WWS, and include folds in the outer retina and thinning of the neuroepithelium ("leopard spots") (Dobyns et al., 1989). In a majority of the MORE-DG null eyes, retinal lamination was largely intact; however, the retina was thin, the ganglion cell layer was disorganized, and ectopic cells were present internal to the inner limiting membrane (Fig. $7 J)$. One-third $(n=3 / 9)$ of the mice examined showed severe retinal dysgenesis and nonattachment (supplemental Fig. 4, available at www.jneurosci.org as supplemental material). Immunofluorescence labeling of laminin showed discontinuous localization at the inner limiting membrane (Fig. $7 \mathrm{~L}$ ).

\section{Discussion}

This study examined the expression and function of dystroglycan in the WWS CNS and the effect of dystroglycan loss on the devel- 
opment of the mouse brain and eye. Biochemical analyses of the WWS brain showed the presence of $\alpha$-dystroglycan in a hypoglycosylated state with loss of affinity for laminin, and embryonic loss of dystroglycan expression in the mouse epiblast produced brain and eye defects that broadly resemble the clinical spectrum of WWS, including severe malformations such as hydrocephalus, microphthalmia, anterior chamber dysgenesis, and retinal dysgenesis and nonattachment.

The posttranslational addition of carbohydrate moieties to $\alpha$-dystroglycan is essential for its ability to bind ligand. Complete chemical deglycosylation of $\alpha$-dystroglycan disrupts its ability to bind laminin (Ervasti and Campbell), and skeletal muscle biopsies of WWS, MEB, and FCMD patients show a loss of $\alpha$-dystroglycan glycosylation and ligand binding (Michele et al., 2002; Kim et al., 2004). Furthermore, the overexpression of the glycosyltransferase LARGE in cultures of patient cells (Barresi et al., 2004) or glycosyltransferase-deficient CHO cells (Patnaik and Stanley, 2005) restores dystroglycan/laminin binding. Clearly, LARGE is important for the posttranslational modification of $\alpha$-dystroglycan; however, mutations of LARGE have been identified in only two cases of WWS (van Reeuwijk et al., 2007, Godfrey et al., 2007). POMT1 mutations are the most prevalent, and they account for $\sim 20 \%$ of WWS cases. Mutations of POMT2, POMGnT1, FKRP, and FCMD have also been identified in some cases, but mutations have not been identified in a majority of WWS patients, suggesting that additional genes and/or mechanisms remain to be identified.

Although it has been previously reported that $\alpha$-dystroglycan glycosylation and ligand binding are disrupted in WWS skeletal muscle (Kim et al., 2004), dystroglycan expression and function had not been examined in WWS brain. $\alpha$-Dystroglycan is differentially glycosylated in skeletal muscle and brain (Ibraghimov-Beskrovnaya et al., 1993), and the mechanisms that account for the tissue-specific variation in $\alpha$-dystroglycan posttranslational modification are not known. On immunoblot of WWS brain, we detected a reduced molecular weight of $\alpha$-dystroglycan $(\sim 90 \mathrm{kDa})$ similar to what has been observed in skeletal muscle (Kim et al., 2004), indicating the disruption of a common step in the posttranslational processing of $\alpha$-dystroglycan. Despite the loss of $\alpha$-dystroglycan glycosylation, a mutation was not identified in the coding region of POMT1 or any of the other known causative genes. The mutation may be present outside the coding region of one of the known causative genes or it may lie in an unknown gene in the biosynthetic pathway of dystroglycan. The large number of WWS cases without a known genetic mutation suggests that additional causative genes remain to be identified.

The dystroglycan null mutation in mice causes early embryonic lethality at embryonic day 6.5 (Williamson et al., 1997), and a previous study reported that the epiblast layers of dystroglycan null mouse embryoid bodies degenerate after several days in culture (Li et al., 2002), suggesting that dystroglycan may be necessary for embryonic survival. Early embryonic lethality in the constitutive null mice may also be attributable to a disruption of Reichert's membrane, an extraembryonic basement membrane that separates maternal and embryonic circulations. To test these hypotheses, we selectively disrupted dystroglycan expression in the mouse epiblast with the Mox2-Cre transgene, which expresses Cre recombinase in epiblast-derived cells beginning at embryonic day 6.5 (Tallquist and Soriano, 2000). The Mox2-Cre transgene is not expressed in extraembryonic structures such as Reichert's membrane, and the restricted spatial and temporal expression of the Mox2-Cre transgene allowed the generation of dystroglycan-deficient mice. These findings support the hypothesis that the disruption of Reichert's membrane, a structure that is specific to rodent development, is the primary cause of embryonic lethality in mice with constitutive null mutation of dystroglycan and suggest that mutations of the dystroglycan gene could also occur in humans.

We have previously shown that tissue-specific loss of dystroglycan in GFAP-Cre/DG null mice causes aberrant neuron migration similar to that observed in type II lissencephaly (Moore et al.). However, these mice failed to reproduce the full spectrum of pathology present in WWS, and the involvement of dystroglycan in eye development was not demonstrated. It was thus possible that genetic heterogeneity or additional glycosyltransferase substrates contribute to the broad clinical spectrum of WWS. Alternatively, the relatively mild phenotype of the GFAP-Cre/DG null mice could also have been attributable to differences in the temporal or spatial patterns of dystroglycan loss in the conditional null animals.

The MOX2-Cre transgenic mouse line drives expression of Cre recombinase during an earlier stage in development than the previously studied GFAP-Cre line (maximal expression at E7.5 vs E14.5, respectively) (Tallquist and Soriano, 2000; Zhuo et al., 2001). In addition, it drives expression of Cre recombinase throughout the entire mouse epiblast, whereas the GFAP-Cre transgene restricts expression to radial glia and astrocytes, silencing dystroglycan in these cells and a subset of neurons that are the progeny of radial glia (Tallquist and Soriano, 2000; Zhuo et al., 2001). Earlier and more global loss of dystroglycan in the MORE-DG null mouse was sufficient to cause malformations that broadly resemble the clinical spectrum of WWS (supplemental Table, available at www.jneurosci.org as supplemental material), including hydrocephalus and ocular malformations that had not been observed in GFAP-CRE/DG null mice (Moore et al., 2002). This implies that earlier and more global loss of dystroglycan during development results in greater disease severity. Our data also show that dystroglycanligand interactions are critical for the integrity of basement membranes in the brain, cornea, and retina. Disruption of this function may be the common basis of the pathogenic mechanisms that lead to abnormal development of these tissues in the mice and in WWS. The role of dystroglycan in brain and eye development may also be relevant to the pathogenic mechanisms of acquired diseases such as lymphocytic choriomeningitis virus (LCMV) encephalitis, which is caused by the LCMV, a virus that binds dystroglycan during host entry and interferes with dystroglycan function (Bonthius et al., 2007; Rojek et al., 2007).

Brain and eye defects are also present in mice with mutations in genes involved in the posttranslational biosynthetic pathway of $\alpha$-dystroglycan that have been linked to a subset of WWS-like clinical cases, including mutations of Large (Grewal et al., 2001; Holzfeind et al., 2002; Michele et al., 2002; Lee et al., 2005), Fcmd (Takeda et al., 2003; Chiyonobu et al., 2005; Kurahashi et al., 2005), and Pomgnt1 (Liu et al., 2006; Yang et al., 2007). The relatively mild phenotypes of the Large and Pomgnt1 mutant mice suggest that some dystroglycan function is preserved in these mouse models. Residual dystroglycan glycosylation may also contribute to the heterogeneous clinical presentation of congenital muscular dystrophies, which ranges from severe congenital muscle pathology with structural brain and eye abnormalities to mild limb-girdle muscular dystrophy (Muntoni and Voit, 2004).

Mutations in known or putative glycosyltransferases have been identified in a fraction of WWS cases, but the genetic underpinnings of this disease are unknown in a majority of cases. 

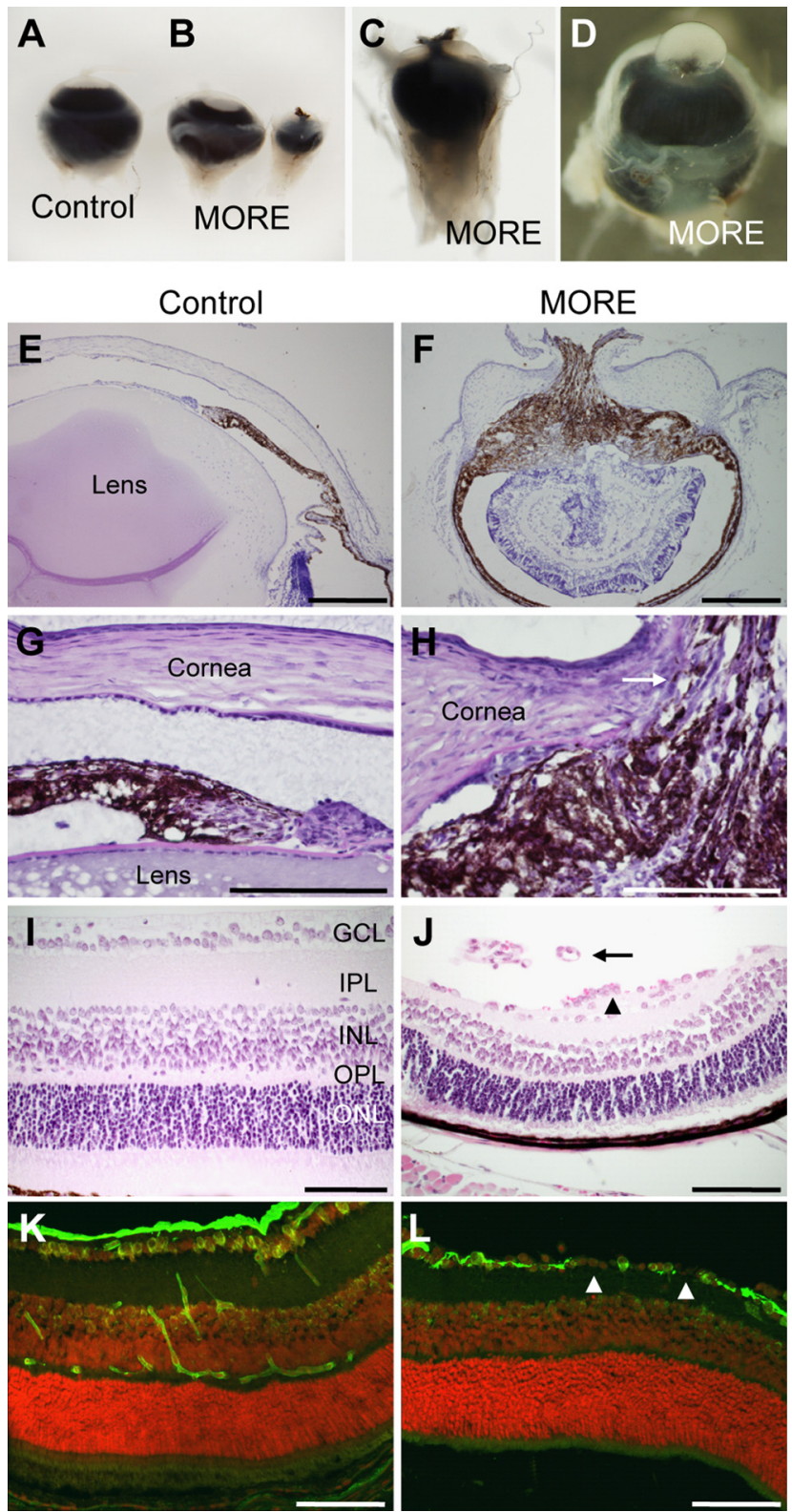

Figure 7. Anterior and posterior chamber dysgenesis in the MORE-DG null eye. $\boldsymbol{A}-\boldsymbol{D}$, Gross anatomy of wild-type $(\boldsymbol{A})$ and MORE-DG null $(\boldsymbol{B}-\boldsymbol{D})$ eyes showing microphthalmia $(\boldsymbol{B}$, $\boldsymbol{C})$ and malformations of the anterior chamber $(\boldsymbol{B}-\boldsymbol{D})$ in the dystroglycan-deficient mouse. $\boldsymbol{E}$, $\boldsymbol{F}$, Hematoxylin- and eosin-stained sections of the anterior chambers of eyes from wild-type littermate $(\boldsymbol{E})$ and MORE-DG null $(\boldsymbol{F})$ mice, showing the absence of a lens and malformation in the dystroglycan-deficient eye. $\boldsymbol{G}, \boldsymbol{H}$, Sections of the anterior eye chambers of wild-type littermate $(\boldsymbol{G})$ and MORE-DG null $(\boldsymbol{H})$ eyes stained with periodic acid Schiff to highlight basement membranes. In the dystroglycan-deficient eye, Descemet's membrane is disrupted, and the corneal and iris tissues are continuous ( $\boldsymbol{H}$, arrow). $\boldsymbol{I}, \boldsymbol{J}$, Hematoxylin- and eosin-stained sections of wild-type littermate $(\boldsymbol{I})$ and MORE-DG null $(\boldsymbol{J})$ retinas, showing a thin neuroepithelium with ectopic cells internal to the inner limiting membrane $(J$, arrowhead). The arrow in $J$ marks the hyaloid artery, which may persist even in a wild-type mouse $<3$ weeks of age. $\boldsymbol{K}, \boldsymbol{L}$, Sections of the wild-type littermate $(\boldsymbol{K})$ and MORE-DG null $(\boldsymbol{L})$ retinas labeled with an antibody to laminin, showing discontinuous laminin expression at the inner limiting membrane of the dystroglycan-deficient retina (arrowheads). Scale bars, $\boldsymbol{E}-\boldsymbol{H}, 1$ $\mathrm{mm} ; \boldsymbol{I}-\mathbf{L}, 200 \mu \mathrm{m}$. GCL, ganglion cell layer; IPL, inner plexiform layer; INL, inner nuclear layer; OPL, outer plexiform layer; $0 \mathrm{NL}$, outer nuclear layer.

One of the relevant issues arising from this lack of complete knowledge is the hypothetical involvement of other substrates that might cause the broad spectrum of pathology or affect the severity of the disease. Although other glycoproteins may be af- fected by the loss of glycosyltransferase activity in WWS, loss of dystroglycan in the mouse is sufficient to produce the broad spectrum of brain and eye pathology present in WWS. These findings indicate that dystroglycan is the key glycosyltransferase substrate relevant to the pathogenic mechanism of the disease. In addition, these findings open up the possibility that WWS cases without any known genetic defect may be caused by novel abnormalities in either the expression or the function of dystroglycan.

\section{References}

Barresi R, Michele DE, Kanagawa M, Harper HA, Dovico SA, Satz JS, Moore SA, Zhang W, Schachter H, Dumanski JP, Cohn RD, Nishino I, Campbell KP (2004) LARGE can functionally bypass alpha-dystroglycan glycosylation defects in distinct congenital muscular dystrophies. Nat Med 10:696-703.

Beltrán-Valero de Bernabé D, Currier S, Steinbrecher A, Celli J, van Beusekom E, van der Zwaag B, Kayserili H, Merlini L, Chitayat D, Dobyns WB, Cormand B, Lehesjoki AE, Cruces J, Voit T, Walsh CA, van Bokhoven H, Brunner HG (2002) Mutations in the O-mannosyltransferase gene POMT1 give rise to the severe neuronal migration disorder WalkerWarburg syndrome. Am J Hum Genet 71:1033-1043.

Beltrán-Valero de Bernabé D, van Bokhoven H, van Beusekom E, Van den Akker W, Kant S, Dobyns WB, Cormand B, Currier S, Hamel B, Talim B, Topaloglu H, Brunner HG (2003) A homozygous nonsense mutation in the fukutin gene causes a Walker-Warburg syndrome phenotype. J Med Genet 40:845-848.

Beltran-Valero de Bernabé D, Voit T, Longman C, Steinbrecher A, Straub V, Yuva Y, Herrmann R, Sperner J, Korenke C, Diesen C, Dobyns WB, Brunner HG, van Bokhoven H, Brockington M, Muntoni F (2004) Mutations in the FKRP gene can cause muscle-eye-brain disease and WalkerWarburg syndrome. J Med Genet 41:e61.

Bonthius DJ, Wright R, Tseng B, Barton L, Marco E, Karacay B, Larsen PD (2007) Congenital lymphocytic choriomeningitis virus infection: spectrum of disease. Ann Neurol 62:347-355.

Chase HB (1942) Studies on an anophthalmic strain of mice. III. Results of crosses with other strains. Genetics 27:339-348.

Chiyonobu T, Sasaki J, Nagai Y, Takeda S, Funakoshi H, Nakamura T, Sugimoto T, Toda T (2005) Effects of fukutin deficiency in the developing mouse brain. Neuromuscul Disord 15:416-426.

Choi BH, Matthias SC (1987) Cortical dysplasia associated with massive ectopia of neurons and glial cells within the subarachnoid space. Acta Neuropathol 73:105-109.

Cohn RD, Henry MD, Michele DE, Barresi R, Saito F, Moore SA, Flanagan JD, Skwarchuk MW, Robbins ME, Mendell JR, Williamson RA, Campbell KP (2002) Disruption of DAG1 in differentiated skeletal muscle reveals a role for dystroglycan in muscle regeneration. Cell 110:639-648.

Cotarelo RP, Valero MC, Prados B, Peña A, Rodríguez L, Fano O, Marco JJ, Martínez-Frías ML, Cruces J (2008) Two new patients bearing mutations in the fukutin gene confirm the relevance of this gene in WalkerWarburg syndrome. Clin Genet 73:139-145.

Dobyns WB, Pagon RA, Armstrong D, Curry CJ, Greenberg F, Grix A, Holmes LB, Laxova R, Michels VV, Robinow M, Zimmerman RL (1989) Diagnostic criteria for Walker-Warburg syndrome. Am J Med Genet 32:195-210.

Duclos F, Straub V, Moore SA, Venzke DP, Hrstka RF, Crosbie RH, Durbeej M, Lebakken CS, Ettinger AJ, van der Meulen J, Holt KH, Lim LE, Sanes JR, Davidson BL, Faulkner JA, Williamson R, Campbell KP (1998) Progressive muscular dystrophy in alpha-sarcoglycan-deficient mice. J Cell Biol 142:1461-1471.

Ervasti JM, Campbell KP (1991) Membrane organization of the dystrophinglycoprotein complex. Cell 66:1121-1131.

Ervasti JM, Campbell KP (1993) A role for the dystrophin-glycoprotein complex as a transmembrane linker between laminin and actin. J Cell Biol 122:809-823.

Gee SH, Montanaro F, Lindenbaum MH, Carbonetto S (1994) Dystroglycan-alpha, a dystrophin-associated glycoprotein, is a functional agrin receptor. Cell 77:675-686.

Godfrey C, Clement E, Mein R, Brockington M, Smith J, Talim B, Straub V, Robb S, Quinlivan R, Feng L, Jimenez-Mallebrera C, Mercuri E, Manzur AY, Kinali M, Torelli S, Brown SC, Sewry CA, Bushby K, Topaloglu H, North K, et al. (2007) Refining genotype phenotype correlations in mus- 
cular dystrophies with defective glycosylation of dystroglycan. Brain 130:2725-2735.

Górecki DC, Derry JM, Barnard EA (1994) Dystroglycan: brain localisation and chromosome mapping in the mouse. Hum Mol Genet 3:1589-1597.

Grewal PK, Holzfeind PJ, Bittner RE, Hewitt JE (2001) Mutant glycosyltransferase and altered glycosylation of alpha-dystroglycan in the myodystrophy mouse. Nat Genet 28:151-154.

Holzfeind PJ, Grewal PK, Reitsamer HA, Kechvar J, Lassmann H, Hoeger H, Hewitt JE, Bittner RE (2002) Skeletal, cardiac and tongue muscle pathology, defective retinal transmission, and neuronal migration defects in the Large(myd) mouse defines a natural model for glycosylation-deficient muscle-eye-brain disorders. Hum Mol Genet 11:2673-2687.

Ibraghimov-Beskrovnaya O, Ervasti JM, Leveille CJ, Slaughter CA, Sernett SW, Campbell KP (1992) Primary structure of dystrophin-associated glycoproteins linking dystrophin to the extracellular matrix. Nature 355:696-702.

Ibraghimov-Beskrovnaya O, Milatovich A, Ozcelik T, Yang B, Koepnick K, Francke U, Campbell KP (1993) Human dystroglycan: skeletal muscle cDNA, genomic structure, origin of tissue specific isoforms and chromosomal localization. Hum Mol Genet 2:1651-1657.

Jayasinha V, Nguyen HH, Xia B, Kammesheidt A, Hoyte K, Martin PT (2003) Inhibition of dystroglycan cleavage causes muscular dystrophy in transgenic mice. Neuromuscul Disord 13:365-375.

Kanoff RJ, Curless RG, Petito C, Falcone S, Siatkowski RM, Pegoraro E (1998) Walker-Warburg syndrome: neurologic features and muscle membrane structure. Pediatr Neurol 18:76-80.

Kim DS, Hayashi YK, Matsumoto H, Ogawa M, Noguchi S, Murakami N, Sakuta R, Mochizuki M, Michele DE, Campbell KP, Nonaka I, Nishino I (2004) POMT1 mutation results in defective glycosylation and loss of laminin-binding activity in alpha-DG. Neurology 62:1009-1011.

Kurahashi H, Taniguchi M, Meno C, Taniguchi Y, Takeda S, Horie M, Otani $\mathrm{H}$, Toda $\mathrm{T}$ (2005) Basement membrane fragility underlies embryonic lethality in fukutin-null mice. Neurobiol Dis 19:208-217.

Lee Y, Kameya S, Cox GA, Hsu J, Hicks W, Maddatu TP, Smith RS, Naggert JK, Peachey NS, Nishina PM (2005) Ocular abnormalities in Large(myd) and Large(vls) mice, spontaneous models for muscle, eye, and brain diseases. Mol Cell Neurosci 30:160-172.

Li S, Harrison D, Carbonetto S, Fassler R, Smyth N, Edgar D, Yurchenco PD (2002) Matrix assembly, regulation, and survival functions of laminin and its receptors in embryonic stem cell differentiation. J Cell Biol 157:1279-1290

Liu J, Ball SL, Yang Y, Mei P, Zhang L, Shi H, Kaminski HJ, Lemmon VP, Hu $\mathrm{H}$ (2006) A genetic model for muscle-eye-brain disease in mice lacking protein O-mannose 1,2-N-acetylglucosaminyltransferase (POMGnT1). Mech Dev 123:228-240.

Manya H, Chiba A, Yoshida A, Wang X, Chiba Y, Jigami Y, Margolis RU, Endo T (2004) Demonstration of mammalian protein O-mannosyltransferase activity: coexpression of POMT1 and POMT2 required for enzymatic activity. Proc Natl Acad Sci U S A 101:500-505.

Michele DE, Barresi R, Kanagawa M, Saito F, Cohn RD, Satz JS, Dollar J, Nishino I, Kelley RI, Somer H, Straub V, Mathews KD, Moore SA, Campbell KP (2002) Post-translational disruption of dystroglycan-ligand interactions in congenital muscular dystrophies. Nature 418:417-422.

Moore SA, Saito F, Chen J, Michele DE, Henry MD, Messing A, Cohn RD, Ross-Barta SE, Westra S, Williamson RA, Hoshi T, Campbell KP (2002) Deletion of brain dystroglycan recapitulates aspects of congenital muscular dystrophy. Nature 418:422-425.

Muntoni F, Voit T (2004) The congenital muscular dystrophies in 2004: a century of exciting progress. Neuromuscul Disord 14:635-649.

Novak A, Guo C, Yang W, Nagy A, Lobe CG (2000) Z/EG, a double reporter mouse line that expresses enhanced green fluorescent protein upon Cremediated excision. Genesis 28:147-155.

Pagon RA, Chandler JW, Collie WR, Clarren SK, Moon J, Minkin SA, Hall JG
(1978) Hydrocephalus, agyria, retinal dysplasia, encephalocele (HARD +/- E) syndrome: an autosomal recessive condition. Birth Defects Orig Artic Ser 14:233-241.

Patnaik SK, Stanley P (2005) Mouse large can modify complex N- and mucin O-glycans on alpha-dystroglycan to induce laminin binding. J Biol Chem 280:20851-20859.

Peng HB, Ali AA, Daggett DF, Rauvala H, Hassell JR, Smalheiser NR (1998) The relationship between perlecan and dystroglycan and its implication in the formation of the neuromuscular junction. Cell Adhes Commun 5:475-489.

Rojek JM, Campbell KP, Oldstone MB, Kunz S (2007) Old World arenavirus infection interferes with the expression of functional alphadystroglycan in the host cell. Mol Biol Cell 18:4493-4507.

Silan F, Yoshioka M, Kobayashi K, Simsek E, Tunc M, Alper M, Cam M, Guven A, Fukuda Y, Kinoshita M, Kocabay K, Toda T (2003) A new mutation of the fukutin gene in a non-Japanese patient. Ann Neurol 53:392-396.

Sugita S, Saito F, Tang J, Satz J, Campbell K, Südhof TC (2001) A stoichiometric complex of neurexins and dystroglycan in brain. J Cell Biol 154:435-445.

Takeda S, Kondo M, Sasaki J, Kurahashi H, Kano H, Arai K, Misaki K, Fukui T, Kobayashi K, Tachikawa M, Imamura M, Nakamura Y, Shimizu T, Murakami T, Sunada Y, Fujikado T, Matsumura K, Terashima T, Toda T (2003) Fukutin is required for maintenance of muscle integrity, cortical histiogenesis and normal eye development. Hum Mol Genet 12:1449-1459.

Tallquist MD, Soriano P (2000) Epiblast-restricted Cre expression in MORE mice: a tool to distinguish embryonic vs. extra-embryonic gene function. Genesis 26:113-115.

Taniguchi K, Kobayashi K, Saito K, Yamanouchi H, Ohnuma A, Hayashi YK, Manya H, Jin DK, Lee M, Parano E, Falsaperla R, Pavone P, Van Coster R, Talim B, Steinbrecher A, Straub V, Nishino I, Topaloglu H, Voit T, Endo $\mathrm{T}$, et al. (2003) Worldwide distribution and broader clinical spectrum of muscle-eye-brain disease. Hum Mol Genet 12:527-534.

van Reeuwijk J, Janssen M, van den Elzen C, Beltran-Valero de Bernabé D, Sabatelli P, Merlini L, Boon M, Scheffer H, Brockington M, Muntoni F, Huynen MA, Verrips A, Walsh CA, Barth PG, Brunner HG, van Bokhoven H (2005) POMT2 mutations cause alpha-dystroglycan hypoglycosylation and Walker-Warburg syndrome. J Med Genet 42:907-912.

van Reeuwijk J, Grewal PK, Salih MA, Beltrán-Valero de Bernabé D, McLaughlan JM, Michielse CB, Herrmann R, Hewitt JE, Steinbrecher A, Seidahmed MZ, Shaheed MM, Abomelha A, Brunner HG, van Bokhoven $\mathrm{H}$, Voit T (2007) Intragenic deletion in the LARGE gene causes WalkerWarburg syndrome. Hum Genet 121:685-690.

Whitley CB, Thompson TR, Mastri AR, Gorlin RJ (1983) Warburg syndrome: lethal neurodysplasia with autosomal recessive inheritance. J Pediatr 102:547-551.

Willer T, Prados B, Falcón-Pérez JM, Renner-Müller I, Przemeck GK, Lommel M, Coloma A, Valero MC, de Angelis MH, Tanner W, Wolf E, Strahl S, Cruces J (2004) Targeted disruption of the Walker-Warburg syndrome gene Pomt1 in mouse results in embryonic lethality. Proc Natl Acad Sci U S A 101:14126-14131.

Williamson RA, Henry MD, Daniels KJ, Hrstka RF, Lee JC, Sunada Y, Ibraghimov-Beskrovnaya O, Campbell KP (1997) Dystroglycan is essential for early embryonic development: disruption of Reichert's membrane in Dag1-null mice. Hum Mol Genet 6:831-841.

Yang Y, Zhang P, Xiong Y, Li X, Qi Y, Hu H (2007) Ectopia of meningeal fibroblasts and reactive gliosis in the cerebral cortex of the mouse model of muscle-eye-brain disease. J Comp Neurol 505:459-477.

Zhuo L, Theis M, Alvarez-Maya I, Brenner M, Willecke K, Messing A (2001) hGFAP-cre transgenic mice for manipulation of glial and neuronal function in vivo. Genesis 31:85-94. 